Introduction Kidsafe Victoria, as part of the Child Accident Prevention Foundation, is the leading non-government, charitable, organisation dedicated to preventing unintentional child injuries and deaths and resulting disabilities. This is achieved through awareness campaigns, education programs, research, advocacy and environmental, legislative and behaviour change.

Background In summer, temperatures inside a parked car can double outside temperatures in a matter of minutes, with a car interior being as much as $30-40^{\circ} \mathrm{C}$ hotter than outside. Yet parents often make the decision to leave their child in the car to run a quick errand. This can lead to dehydration or even death, as young children are not able to regulate their body temperature as well as adults. In most states in Australia, it is against the law to leave a child unattended in a vehicle.

Objective To identify the number of children being left unattended in hot cars in Victoria, Australia using existing research and collating new data.

Results Statistics from a singular motoring organisation in Victoria showed that between 2008 and 2009, 1543 children needed rescuing from a locked car. Results from a study collating more comprehensive data will be discussed.

Future Implications This study forms part of an ongoing educational campaign raising awareness of the dangers of leaving children in cars, especially on a hot day. Integration of the findings from the components of this study will provide strong evidence to inform future campaigns regarding legislative and policy changes to help protect children.

\title{
0692 INCIDENCE OF CHILDREN LEFT UNATTENDED IN HOT CARS IN VICTORIA, AUSTRALIA
}

J J Killian*, M Water, M Stokes, L Hallett Correspondence: Kidsafe Victoria, c/o Deakin University School of Psychology 221 Burwood Highway, Burwood 3125, Australia 